K.P. Geigle, R. Hadef, W. Meier, Soot formation and flame characterization of an aero-engine model combustor burning ethylene at elevated pressure, J. Eng. Gas Turbines Power 136 (2), 2014, 021505-1 - 021505-7 (2014).

The original publication is available at

http://dx.doi.org/10.1115/1.4025374 


\title{
Soot formation and flame characterization of an aero-engine model combustor burning ethylene at elevated pressure
}

\author{
Klaus Peter Geigle ${ }^{1}$, Redjem Hadef ${ }^{2}$, Wolfgang Meier ${ }^{1}$ \\ ${ }^{1}$ German Aerospace Center (DLR) Institute of Combustion Technology, Stuttgart, Germany \\ ${ }^{2}$ Université Larbi Ben M'Hidi Institut de Génie Mécanique, Oum El Bouaghi, Algerie \\ Corresponding author: klauspeter.geigle@dlr.de \\ Phone: ++49-711-6862-398 \\ Fax: ++49-711-6862-578
}

\begin{abstract}
Swirl-stabilized, non-premixed ethylene/air flames were investigated at pressures up to 5 bars to study the effect of different operating parameters on soot formation and oxidation. Focus of the experiments was the establishment of a data base describing well defined flames, serving for validation of numerical simulation. Good optical access via pressure chamber windows and combustion chamber windows enables application of laser-induced incandescence to derive soot volume fractions after suitable calibration. This results in ensemble averaged as well as instantaneous soot distributions. Beyond pressure, parameters under study were the equivalence ratio, thermal power and amount of oxidation air. Latter could be injected radially into the combustor downstream of the main reaction zone through holes in the combustion chamber posts. Combustion air was introduced through a dual swirl injector whose two flow rates were controlled separately. The split of those air flows provided an additional parameter variation. Nominal power of the operating points was approximately $10 \mathrm{~kW} / \mathrm{bar}$ leading to a maximum power of roughly $50 \mathrm{~kW}$, not including oxidation air.
\end{abstract}

[Keywords: gas turbine model combustor, laser diagnostics, soot] 


\section{INTRODUCTION}

The reduction of soot emissions is one of the key issues in the development of new aero-engines. Combustion modeling can serve to optimize engines with respect to different parameters such as flame stability, efficiency and pollutant formation, including soot emissions. One reason for the still relatively poor predictive capability of those models is the complexity of soot chemistry. To date, computational capabilities cannot handle a very detailed chemistry and turbulence modeling on a fine computational grid for complex combustor geometries. Therefore, simplifications of the models are required and measurements under relevant conditions are needed for the validation of numerical tools. So far, experimental data sets suited for model validation are restricted to laminar or simple turbulent jet flames, for example $[1,2]$. While technically relevant flames can well serve to improve the understanding of soot formation $[3,4]$, they are frequently too complex for model validation, or do not provide the required knowledge of boundary conditions. The presented study intends to bridge the gap between recent detailed experiments in atmospheric jet [2] or swirl flames [5] and fully technical combustion, i.e. focuses on pressurized flames under well-defined and technically relevant conditions. Pressurized turbulent flames are challenging with respect to application of accurate laser-based diagnostics and sufficiently well-defined experimental conditions. Based on experiences from an earlier project [6] we built a new gasturbine model combustor for swirling partially-premixed flames at elevated pressure. As in previous experiments, ethylene is used as a "model fuel" because of simpler combustion chemistry compared to kerosene, and absence of the experimentally and numerically highly challenging droplet treatment. One significant improvement is the separate control of the swirled air in-flows and the optimized geometry of oxidation air injection. Interaction of this additional air, injected after two thirds of the combustor length from the four corners of the combustion chamber with the combustion products mimics cooling air injection of technical combustors, having a significant impact on soot oxidation and thus emissions.

The results are presented as time averaged soot distributions and, where suited, as instantaneous soot volume fraction maps. The available data set should serve for validation of modern modeling tools for soot prediction such as $[7,8]$.

\section{EXPERIMENTAL SETUP}




\section{Burner configuration and test rig}

The burner is similar to the one described by Geigle et al. [5] and references therein, and consists of three concentric flows. Air at room temperature is supplied to the flame through a central (diameter $12.3 \mathrm{~mm}$ ) and an annular nozzle (inner diameter $14.4 \mathrm{~mm}$, outer diameter $19.8 \mathrm{~mm}$ ). The air flows are fed from separate pleni and pass radial swirlers consisting of 8 channels (width $\mathrm{w}=4.2 \mathrm{~mm}$, height $\mathrm{h}=5.4 \mathrm{~mm}$ ) for the central nozzle and 12 channels $(\mathrm{w}=3.2 \mathrm{~mm}, \mathrm{~h}=4.5 \mathrm{~mm})$ for the annular nozzle. Gaseous fuel $\left(\mathrm{C}_{2} \mathrm{H}_{4}\right)$ is injected in between both air flows through 60 straight channels $(0.5 \times 0.4$ $\mathrm{mm}^{2}$ ) forming a concentric ring. Thus, the fuel placement mimics the atomizing lip between swirled air flows as used for spray flames. The exit planes of the fuel and air flows are located at the level of the combustion chamber inlet, being defined as height $h=0$. This allows full optical access to the fuel injection, in contrast to previous experiments $[5,6]$. The combustion chamber measures $120 \mathrm{~mm}$ in height and has a square section of $68 \times 68 \mathrm{~mm}^{2}$ with beveled edges (see Figure 1). Four quartz windows $(127 \mathrm{~mm} \times 59 \mathrm{~mm} \times 3 \mathrm{~mm})$ are mounted between four water-cooled metal posts yielding excellent optical access of $51.4 \mathrm{~mm} \times 120 \mathrm{~mm}$ to the flame. The water-cooled top plate has a cylindrical exhaust hole (diameter $40 \mathrm{~mm}$, length $24 \mathrm{~mm}$ ), linked to the combustion chamber by a curvature The high velocity in the exhaust tube prevents any backflow from outside the combustion chamber. Each of the four corner posts has an additional air duct of 5 $\mathrm{mm}$ diameter for the injection of secondary air into the combustor at a height of $80 \mathrm{~mm}$. A metal plate shields the injector nozzle's top plate from the hot combustion gases during operation. This is required because of the lack of external cooling of this part.

The combustor is mounted in a water-cooled steel pressure housing with large optical access $\left(60 \times 120 \mathrm{~mm}^{2}\right)$, that has been used for other studies in the past $[6,9,10]$. The pressure inside the housing is adjusted by partially blocking the exhaust port with a movable piston. An air flow through the gap between the combustion chamber and the pressure housing serves as air cooling for the windows of the combustion chamber. The inner surface of the windows does not show any melting or other thermal damage during operation, but exhibits some soot deposition for certain operating conditions. The surface temperature is estimated to be between 500 and $900{ }^{\circ} \mathrm{C}$, depending on the position relative to the location of the flame. For modeling purposes, the quartz window transmission curves can serve to estimate the radiative energy balance. 


\section{Flame parameters}

The burner including the cooling system was designed for operation at approximately $10 \mathrm{~kW} / \mathrm{bar}$ thermal power providing Re numbers satisfying modelers' needs. The flow rates applied for the different operating ranges, given in standard liters per minute (slpm), are shown in Table 1 together with corresponding Re numbers. The air and fuel flows were controlled using electronic mass flow controllers (Bronkhorst) which were carefully calibrated in-house; accuracy of the calibration is estimated to be below $1 \%$ of the maximum flow rates. The equivalence ratio $\phi$ and thermal power $P$ were calculated from the primary air flow rate $Q_{\text {air }}$ as a sum of central $\left(Q_{\text {air,c }}\right)$ and ring air $\left(Q_{\text {air, }}\right)$, whereas the global equivalence ratio $\phi_{\text {global }}$ and the global thermal power $P_{\text {global }}$ were calculated from the total air flow rate, $Q_{\text {air }}+Q_{\text {oxi }}$. The variable amount of oxidation air is given as fraction $Q_{\text {oxi }} / Q_{\text {air }}$. Note that due to the excess fuel the value for $P$ is purely a function of the combustion air mass flow in most cases whereas $\phi_{\text {global }}$ changes to lean after injection of oxidation air and thus $P_{\text {global }}$ depends on the fuel mass flow. The air split ratio is defined as the ratio of central air to the total combustion air $Q_{\text {air,c }} / Q_{\text {air. }}$. The value of 0.3 for the reference flame conditions is chosen to resemble values deduced from simulations of a similar non-sooting burner with known velocity profiles [11,12]. For even higher values the sooting region shifts towards the flame periphery, leading to increased soot pollution on the inner surface of the combustion chamber windows.

From previous measurements in a similar combustor it is known that the flow field consists of a conically shaped inflow region with relatively high flow velocities, an inner and an outer recirculation zone and the shear layers between the inflow and the recirculating flow $[5,11]$.

\section{Optical setup}

The optical setup is similar to that described in [5]. In addition to LII experiments, OH chemiluminescence measurements were performed simultaneously to capture the region of the main flame zone. For the excitation of LII we used a $10 \mathrm{~Hz}$ pulsed Nd:YAG laser (Brilliant B, Quantel) at $1064 \mathrm{~nm}$ with a pulse duration of $9 \mathrm{~ns}$. A set of sheet forming optics ( $f=-50 \mathrm{~mm}$ cylindrical lens, $f=1000 \mathrm{~mm}$ spherical lens, rectangular aperture) was used to form a uniform sheet of $30 \mathrm{~mm}$ height and approximately $300 \mu \mathrm{m}$ thickness (Fig. 2, left and centre - measurements performed with a beam profiler). An 
attenuator composed of a lambda half retardation plate and a Glan laser polarizer was used to adjust the sheet energy to approx. $32 \mathrm{~mJ}$, allowing measurements well in the LII plateau regime [13]. The LII response curve was determined in a well characterized stationary flame [14], equally serving for calibration just before the measurements in the pressurized swirl flame. For the fluence curve shown in Fig. 2, right, the LII signal detected in the indicated tiny rectangle was plotted versus laser fluence. For other locations in the flame the LII response is very similar, confirming the vertical homogeneity of the laser sheet. The laser sheet passes through the burner axis.

The LII emission was collected perpendicularly to the laser sheet through an interference filter at $\lambda=450 \pm 10 \mathrm{~nm}$ (LOT). The signal was recorded by an intensified double frame CCD camera (Dicam Pro, PCO) with gates of $60 \mathrm{~ns}$, the first one before the laser shot to capture the background flame luminosity, the second one starting simultaneously with the laser pulse. The laser sheet was vertically traversed through the flame by a translation stage, while the LII camera was kept fix capturing the full combustion chamber view at once. $\mathrm{OH}$ chemiluminescence was separated from the LII by a dichroic mirror (HR $308 \mathrm{~nm}$ ) in combination with an additional interference filter ( $\lambda=315 \pm 10 \mathrm{~nm}$, Hugo Anders) and measured by a second ICCD camera (Flamestar 2, LaVision). The $40 \mu$ s long gate of this camera was delayed by $2 \mu$ s with respect to the laser pulse to avoid interferences with the LII process. It was equipped with a Nikon UV lens ( $f=105 \mathrm{~mm}$, F4.5) in contrast to the LII camera that was using a Nikon VIS camera objective ( $f=105 \mathrm{~mm}, \mathrm{~F} 2.5)$. The frame rates of the combined cameras allowed the acquisition of one image every $400 \mathrm{~ms}$. With this setup LII and OH chemiluminescence could be recorded simultaneously, but a comparison on a single-shot basis is of limited value, because LII yields the soot concentrations in the laser excitation plane, whereas $\mathrm{OH}$ chemiluminescence provides line-of-sight integrated images of relatively low temporal resolution. As additional information, the line-of-sight integrated soot emission was recorded with the LII camera, having the laser blocked, and with a gate of $3 \mu \mathrm{s}$.

In order to provide absolute soot concentrations the LII images need to be calibrated. For that purpose a well characterized laminar diffusion flame [14] was mounted at the same position as the GT model combustor and LII images were acquired with the same optical geometry and settings. The experimental uncertainty of the soot concentration is based on uncertainties of the reference soot concentrations, remaining weak laser sheet inhomogeneity, and the lack of knowledge of the local laser fluence in the flame, influenced by laser absorption and, more severe, beam steering [15]. 
The resulting uncertainty is estimated to be $30 \%$. Transfer of an atmospheric calibration to pressurized target flames is influenced by decreasing LII signal decay times. However, for the pressure range considered here (1 to 5 bars), this effect is neglected. Similarly neglected is the effect of signal trapping on the detection pathway. The latter is justified by the relatively low product of soot concentrations and soot filament size. As long as the combustor windows are not covered with soot deposits, this effect is estimated to decrease measured soot concentrations by no more than $10 \%$ for single shots in the strongest sooting case. The effect becomes negligible for time averaged soot distributions because of the statistics of the occurrence of soot filaments.

\section{RESULTS}

General flame features are displayed in Fig. 3, showing a collection of images obtained by different diagnostics for the reference flame at 3 bars. The photo (left) is close to the visual impression, however with a relatively short exposure time of $500 \mu \mathrm{s}$. The orange soot streaks are clearly visible, and, with a lower intensity, also the bluish flame front region at the flame base. Luminous soot is visible over large regions of the combustion chamber with lower intensities close to the nozzle. The second image of the sequence represents the time-averaged soot luminosity emitted around $450 \mathrm{~nm}$, i.e. the spectral region for the detection of the LII signal. This image indicates low soot concentration close to the bottom of the combustion chamber - no significant amount of soot is transported to this region nor is strong soot formation taking place close to the injector. Further downstream this image indicates the onset of soot oxidation once additional oxidation air gets injected after $2 / 3$ of the combustor. However, soot luminosity is not a reliable measure for soot concentrations because the luminosity depends also on the temperature of the soot. The next image was recorded by LII and visualizes an instantaneous soot distribution in the second lowest laser excitation plane. Similar to [5] the soot filaments (blue) are quite small and mostly not connected. In contrast to the case at atmospheric pressure [5], no long filaments appear under pressurized conditions. Soot events are very localized and exhibit strong gradients. 400 instantaneous images are required to yield a relative smooth average distribution. The next image shows a concatenation of time-averaged LII images for all sheet positions. Here, the main features of swirl flames can be recognized. Major soot formation occurs in cone-shaped region that extends far downstream. In the lower part of the combustion chamber, this region coincides largely with the 
inner recirculation zone where hot exhaust gases containing unburned hydrocarbons come into contact with fresh gases and the flame zone [4]. The flame zone and region of inflowing fresh gas are characterized by low or no soot concentrations in this image. The influence of the additional oxidation air jets, impinging to the burner axis, leads to reduced soot concentration on the combustor axis downstream of the second laser sheet position, i.e. even significantly upstream of the injection position (details on this effect in a subsequent section). This effect was already described by Lammel et al. [6] who measured the influence of the cold secondary air admixture on the flame axis of similar flames with CARS. The right image displays an Abel-transformed $\mathrm{OH}$ chemiluminescence distribution which represents the location of the flame zone. This image matches the soot-free region of the averaged LII distribution.

Fig. 4 displays the influence of oxidation air on the soot distribution in a more quantitative manner. The flame visualized in the left image as ensemble-averaged soot distribution is operated without oxidation air. Soot concentrations in the inner recirculation zone show peak values of approximately $70 \mathrm{ppb}$, i.e. $1 \%$ of the peak values in the laminar diffusion flame used for calibration. The central portion of the combustor shows non-negligible values from the inner recirculation zone up to the combustor exit. No soot is present in the inflow and flame front region while smaller soot concentrations exist in the outer recirculation zones close to the burner plate. Addition of $40 \%$ oxidation air (central image) completely removes any soot in the central region of the combustor far upstream into the inner recirculation zone, and reduces the soot concentration levels by half in the rest of the flame. Further increase of the oxidation air flow (right image) reduces the peak soot concentrations even more to values of about 10-15 ppb. More and more single soot events remain visible in the ensemble-average. This is indicative for the fact that the number of soot filaments in a sequence of instantaneous images decreases with increasing amount of oxidation air. Soot filaments become quite sparse, particularly in the lower parts of the inner recirculation zone. For these flame conditions the soot-free region near the inflow is wider, while soot concentrations in the outer recirculation zone are less influenced.

In Fig. 5 the influence of thermal power is shown. This variation corresponds to an increase of inflow velocity and Reynolds number (see Table 1), respectively. The general flame shape is hardly affected while the inflow and flame front region is wider for the higher power test case. Lower soot volume fraction levels can be explained by a smaller number of soot events as deduced from a statistical analysis of the instantaneous images (not shown). For higher inflow velocities 
soot concentrations in the lower part of the inner recirculation zone are low compared to the anyways low soot concentrations. Higher inflow velocities lead to improved mixing so that the probability of rich zones with increased soot formation decreases.

Fig. 6 visualizes two parameter variations relative to the reference flame shown in the centre. The flame displayed to the left has a lower central air flow. This correlates with a wider opening of the inflow and the flame zone cone. Almost no soot is present in the outer recirculation zone under these conditions. This coincides with a wider soot free region in the central part of the combustor and less soot further upstream. When the pressure is increased relative to the reference flame (right image), soot concentrations increase by roughly a factor of four. The upstream edge of the soot distribution and the absence of soot in the outer recirculation zone are similar to the left flame in this figure (different air split). This strong pressure influence on soot formation is well known from literature $[6,16]$ and motivates the demand for pressure studies from industry, as this factor essentially needs improved understanding.

For the pressure of 5 bars Fig. 7 represents the influence of the equivalence ratio $\phi$. Even at globally substoichiometric mixture of $\phi=0.9$ the existence of locally rich zones leads to (occasional) soot formation. Soot formation is mainly concentrated to the inner recirculation zone in all cases, while soot persists significantly further downstream for the fuel-rich test cases. The secondary air decreases soot concentration levels down to zero in the central part of the combustor for all equivalence ratios studied. However, for the fuel-rich operating points the mixture of oxidation air with combustion products from the main flame zone is not fast enough to remove the soot completely in the upper half of the combustor, even if the global equivalence ratio is smaller than one. The history of fluid elements moving through the combustor and local mixture fraction are highly relevant for the presence of soot filaments as discussed further below. The high-momentum radially-injected secondary air jets $\left(45^{\circ}\right.$ relative to the visualized plane) do not mix well enough with the soot-laden flow in the imaging plane. In the context of varying the equivalence ratio it should be noted that the soot threshold for premixed ethylene flames at atmospheric pressure is at $\phi=1.8$, i.e. significantly higher than in our flames consequently, we estimate the local equivalence ratio even for the sub-stoichiometric case to be much higher than the global value, while the location of these spots varies strongly due to turbulence and local mixture. A further decrease of 
equivalence ratio immediately changed the flame behavior to noisy with a different flame shape and disappearance of any soot streaks.

Fig. 8 shows typical representations of instantaneous soot distributions for different flames. For each sheet position one representative image is arbitrarily chosen. In all cases, peak soot concentrations are significantly higher than in the time-averaged images discussed above. This is due to the high tempo-spatial dynamics of soot formation and the correlated high intermittency flattening out the time averages. Soot sheets in the 1 bar flame exhibit similar shapes as in the atmospheric flame described in [5]. Soot streaks can be relatively long and are spatially separated. The 3 bar reference flame (centre) has comparable peak soot concentrations but a higher number of small soot structures, located in the shear layer between inner recirculation zone and inflow, as well as at larger radial positions further downstream.

In contrast, the same flame without oxidation air (right) shows a significant number of small soot filaments everywhere in the inner recirculation zone and further downstream. These single shot representations explain the time averages of the two flames discussed above: The higher soot load of the flame without oxidation air is mainly due to a larger number of soot segments and not an increased peak intensity.

Fig. 9, top row, visualizes the probability of finding soot in a certain position for those two flames (left, centre). The probability of finding soot rises from $7.5 \%$ in distinct locations for the reference flame up to $18 \%$ and a larger spread through the whole flame when removing oxidation air.

A more detailed statistical study for these two flames is shown as histograms, analyzing the number of segments per image. Soot filaments or segments are identified by a threshold intensity criterion, excluding very small events typical for image intensifier noise. This analysis reveals that the difference seen in the averaged soot concentrations (Fig. 4) is mainly due to a larger number of soot filaments per image for the flame without oxidation air (slight right shift of distribution in Fig. 9, bottom row for the lowest laser sheet position). In addition, filaments have a moderately larger size (not shown here). The typical peak intensities in those sheets are relatively uninfluenced. Further downstream in the flames (Fig. 9, second row), the number of segments per image is strongly influenced by addition or absence of oxidation air directly affecting the probability of finding soot in these regions and thus the average soot concentrations. When the pressure is varied relative to the reference case, the probability of soot events in a single location changes significantly (Fig. 9, right 
column). Besides a further increase of the number of segments per image relative to the reference flame (histograms in right column of Fig. 9), other quantities increase in addition.

Fig. 10 shows a comparison of instantaneous soot distribution for both flames, the reference flame at 3 bars (left) and the corresponding 5 bar flame (right). The upper three images are "typical" representatives for each sequence recorded in the second sheet position, the lowest image is a strongly sooting representative. It must be noted that the instantaneous images show very strong tempo-spatial dynamics; this concerns number and size of soot events per image, peak intensities (all of these covering the full range from zero to maximum) and location. The weakest sooting representative would typically be a dark image (no soot at all) not visualized here. Those high variabilities of soot distributions strongly depend on local gas composition, i.e. chemical history of the fluid volume moving through the combustor, combined with flow field effects causing strain and dilution. This intermittency of soot events in instantaneous images has been described for example by Qamar [17]. The visual impression given by these distributions can be quantitatively described by the histograms below analyzing the full set of instantaneous images per sequence recorded in this location. They show that typical peak intensities in the images increase with pressure (top row of histograms), as well as that the average segment size increases (bottom row of histograms). However, in all cases soot structures remain quite localized indicating the strong dependency on local composition, particularly mixture and flow field. Consequently, flow field measurements are planned in these flames as future extension of the data set.

These examples demonstrate that the instantaneous soot distribution is completely different from averaged distributions, while the size of soot filaments at increased pressure is typically still very small, gradients are strong and peak concentrations exceed $1 \mathrm{ppm}$.

\section{SUMMARY AND OUTLOOK}

A gas turbine model combustor with very good optical access was used to stabilize non-premixed, fuel-rich, sooting $\mathrm{C}_{2} \mathrm{H}_{4} /$ air flames at pressures up to 5 bars. In order to oxidize the soot, secondary air was injected further downstream. Laser-induced incandescence (LII) was successfully applied to determine single-shot 2D soot concentrations and derive time averages. Most sensitive for soot formation are the chamber pressure and the equivalence ratio. Both influence soot concentrations, and the shape and area of formed soot filaments. The air split between the inner and outer air nozzles has 
an influence on the position of soot-rich regions. Increasing the mass flow rates at a given pressure and equivalence ratio improves mixing, thus reduces fuel rich zones and decreases soot formation. In addition to the measurement of the timeaveraged soot distributions the shapes of soot filaments were analyzed. These are important for a correct interpretation of the flame behavior and must be considered in modeling of technically relevant combustion under sooting conditions.

The main goals of the experiments were the investigation of soot formation and oxidation in turbulent sooting flames, the study of different influencing parameters and the establishment of a data base for the validation of numerical simulations.

Future work will be devoted to application of further optical diagnostics, specifically the measurements of the flow field and temperatures.

\section{ACKNOWLEDGMENTS}

The authors want to thank P. Oßwald for experimental assistance. Part of this work was funded by the European Commission within the project Fuel Injector Research for Sustainable Transport (FIRST) under contract no. 265848.

\section{REFERENCES}

[1] Mandatori P.M., Gülder Ö.L., 2011, "Soot Formation in Laminar Ethane Diffusion Flames at Pressures from 0.2 to 3.3 MPa”, Proc. Combust. Inst. 33, pp. 577-584.

[2] Köhler M., Geigle K.P., Blacha T., Gerlinger P., Meier W., 2012, "Experimental Characterization and Numerical Simulation of a Sooting Lifted Turbulent Jet Diffusion Flame”, Combust. Flame 159, pp. 2620-2635.

[3] Carl M., Behrendt T., Fleing C., Frodermann M., Heinze J., Hassa C., Meier U.E., Wolff-Gaßmann D., Hohmann S., Zarzalis N., 2001, "Experimental and Numerical Investigation of a Planar Combustor Sector at Realistic Operating Conditions”, J. Eng. Gas Turb. Power 123, pp. 810-816.

[4] Meyer T.R., Roy S., Belovich V.M., Corporan E., Gord J.R., 2005, "Simultaneous Planar Laser-Induced Incandescence, OH Planar Laser-Induced Fluorescence, and Droplet Mie Scattering in Swirl-Stabilized Spray Flames", Appl. Opt. 44, pp. 445-454. 
[5] Geigle K.P., Zerbs J., Köhler M., Stöhr M., Meier W., 2011, “Experimental Analysis of Soot Formation and Oxidation in a Gas Turbine Model Combustor Using Laser Diagnostics”, J. Eng. Gas Turb. Power 133 (12), pp. 121503-1 - $121503-$ 9, 2011.

[6] Lammel O., Geigle K.P., Lückerath R., Meier W., Aigner M., 2007, "Investigation of Soot Formation and Oxidation in a High-Pressure Gas Turbine Model Combustor by Laser Techniques”, Proc. ASME Turbo Expo 2007: Power for Land, Sea and Air, GT2007-27902, 14.-17.05.2007, Montreal (Canada).

[7] Blacha T., Di Domenico M., Gerlinger P., Aigner M., 2011, "Soot Predictions in Premixed and Non-Premixed Flames Using a Sectional Approach for PAHs and Soot”, Combust. Flame 159, pp. 181-193.

[8] Donde P., Raman V., Mueller M.E., Pitsch H., 2013, “LES/PDF Based Modeling of Soot-Turbulence Interactions in Turbulent Flames“, Proc. Combust. Inst. 34, pp. 1183-1192.

[9] Tsurikov M.S., Geigle K.P., Krüger V., Schneider-Kühnle Y., Stricker W., Lückerath R., Hadef R., Aigner M., 2005, "Laser-Based Investigation of Soot Formation in Laminar Premixed Flames at Atmospheric and Elevated Pressures", Combust. Sci. Technol. 177, pp. 1835-1862.

[10] Tsurikov M.S., Meier W., Geigle K.P., 2006, "Investigations of a Syngas-Fired Gas Turbine Model Combustor by Planar Laser Techniques”, Proc. ASME Turbo Expo 2006: Power for Land, Sea and Air, GT2006-90344, May 8-11, 2006, Barcelona (Spain).

[11] Weigand P., Meier W., Duan X.R., Stricker W., Aigner M., 2006, “Investigations of Swirl Flames in a Gas Turbine Model Combustor. Part I: Flow Field, Structures, Temperature, and Species Distributions”, Combust. Flame 144, pp. 205224.

[12] Rebosio F., Widenhorn A., Noll B., Aigner M., 2010, "Numerical Simulation of a Gas Turbine Model Combustor Operated Near the Lean Extinction Limit”, Proc. ASME Turbo Expo 2010: Power for Land, Sea and Air, GT2010-22751, 14-18.06.2010, Glasgow (UK).

[13] Santoro R.J., Shaddix C.R., 2002, "Laser-Induced Incandescence”. In Kohse-Höinghaus K., and Jeffries J. (Eds.) Applied Combustion Diagnostics, Taylor and Francis, London, Chap. 9. 
[14] Trottier S., Guo H., Smallwood G.J., Johnson M.R., 2007, “Measurement and Modeling of the Sooting Propensity of Binary Fuel Mixtures”, Proc. Combust. Inst. 31, pp. 611-619.

[15] Zerbs J., Geigle K.P., Lammel O., Hader J., Stirn R. , Hadef R., Meier W., 2009, “The Influence of Wavelength in Extinction Measurements and Beam Steering in Laser-Induced Incandescence Measurements in Sooting Flames”, Appl. Phys. B 96, pp. 683-694.

[16] Karatas A.E., Gülder Ö.L., 2012, "Soot Formation in High Pressure Laminar Diffusion Flames", Prog. Energ. Combust. 38, pp. 818-845.

[17] Qamar N.H., Alwahabi Z.T., Chan Q.N., Nathan G.J., Roekaerts D., King K.D., 2009, "Soot Volume Fraction in a Piloted Turbulent Jet Non-Premixed Flame of Natural Gas”, Combust. Flame 156, pp. 1339-1347. 


\begin{tabular}{cccccccccccccc}
\hline $\begin{array}{c}p \\
{[\mathrm{bar}]}\end{array}$ & $\phi$ & $\begin{array}{c}P_{\text {primary }} \\
{[\mathrm{kW}]}\end{array}$ & $\begin{array}{c}Q_{\text {air,c }} \\
{[\mathrm{slpm}]}\end{array}$ & $\begin{array}{c}R e_{\mathrm{c}} \\
/ 1000\end{array}$ & $\begin{array}{c}Q_{\text {air, }} \\
{[\mathrm{slpm}]}\end{array}$ & $\begin{array}{c}R e_{\mathrm{r}} \\
/ 1000\end{array}$ & $\begin{array}{c}Q_{\text {fuel }} \\
{[\mathrm{slpm}]}\end{array}$ & $\begin{array}{c}Q_{\text {oxi }} \\
{[\mathrm{slpm}]}\end{array}$ & $\begin{array}{c}R e_{\text {total }} \\
/ 1000\end{array}$ & $Q_{\text {air, }} / Q_{\text {air }}$ & $Q_{\text {oxi }} / Q_{\text {air }}$ & $\phi_{\text {global }}$ & $\begin{array}{c}P_{\text {global }} \\
{[\mathrm{kW}]}\end{array}$ \\
\hline 1 & 1.0 & 2.1 & 15.6 & 2 & 15.6 & 0.8 & 2.2 & 0 & 2.7 & 0.5 & 0 & 1.0 & 2.1 \\
3 & 1.2 & 32.2 & 46.8 & 5.9 & 420.9 & 21.2 & 39.3 & 187.4 & 40.6 & 0.1 & 0.4 & 0.86 & 38.6 \\
3 & 1.2 & 32.2 & 140.8 & 17.8 & 328.5 & 16.5 & 39.3 & 0 & 40.8 & 0.3 & 0 & 1.2 & 32.2 \\
$\mathbf{3}$ & $\mathbf{1 . 2}$ & $\mathbf{3 2 . 2}$ & $\mathbf{1 4 0 . 8}$ & $\mathbf{1 7 . 8}$ & $\mathbf{3 2 8 . 5}$ & $\mathbf{1 6 . 5}$ & $\mathbf{3 9 . 3}$ & $\mathbf{1 8 7 . 4}$ & $\mathbf{4 0 . 8}$ & $\mathbf{0 . 3}$ & $\mathbf{0 . 4}$ & $\mathbf{0 . 8 6}$ & $\mathbf{3 8 . 6}$ \\
3 & 1.2 & 32.2 & 140.8 & 17.8 & 328.5 & 16.5 & 39.3 & 279.8 & 40.8 & 0.3 & 0.6 & 0.75 & 38.6 \\
3 & 1.2 & 42.9 & 187.5 & 23.7 & 436.4 & 21.9 & 52.3 & 249.7 & 54.2 & 0.3 & 0.4 & 0.86 & 51.5 \\
5 & 0.9 & 53.7 & 259.9 & 32.9 & 607.8 & 30.6 & 54.5 & 347.1 & 75.3 & 0.3 & 0.4 & 0.64 & 53.7 \\
5 & 1.0 & 53.7 & 234.2 & 29.6 & 546.2 & 27.5 & 54.5 & 312.1 & 67.8 & 0.3 & 0.4 & 0.71 & 53.7 \\
5 & 1.1 & 53.7 & 234.2 & 29.6 & 546.2 & 27.5 & 59.8 & 312.1 & 67.8 & 0.3 & 0.4 & 0.79 & 59.0 \\
5 & 1.2 & 53.7 & 234.2 & 29.6 & 546.2 & 27.5 & 65.4 & 312.1 & 67.8 & 0.3 & 0.4 & 0.86 & 64.4 \\
\hline
\end{tabular}

Table 1. Flame parameters for typical flames: Pressure, $p$, mass flows for air through burner (central and ring), $Q_{\text {air,c, }}$, and $Q_{\text {air, }}$, fuel, $Q_{\text {fuel }}$, oxidation air through secondary air inlet, $Q_{\text {oxi }}$, equivalence ratios, $\phi, \phi_{\text {global }}$, thermal powers, $P$, $P_{\text {global, }}$ and fractions $Q_{\text {air,c }} / Q_{\text {air }}$ and $Q_{\text {oxi }} / Q_{\text {air }}$ with $Q_{\text {air }}=Q_{\text {air,c }}+Q_{\text {air,r }}$. The reference flame is indicated bold. Flow rates are referenced to 1.013 bar and $273 \mathrm{~K}$.

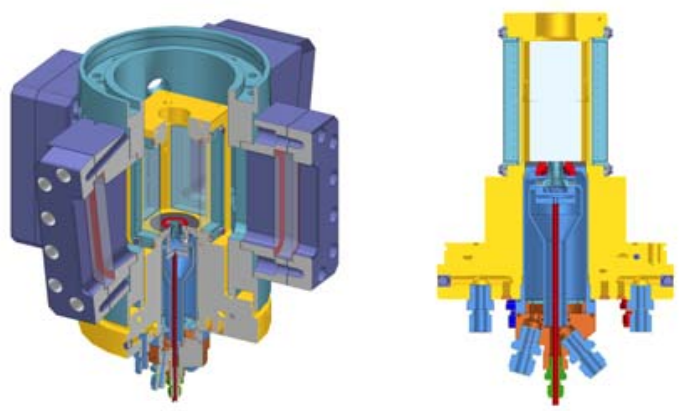

Fig. 1: Design of burner, combustion chamber and optical module of pressure housing. 

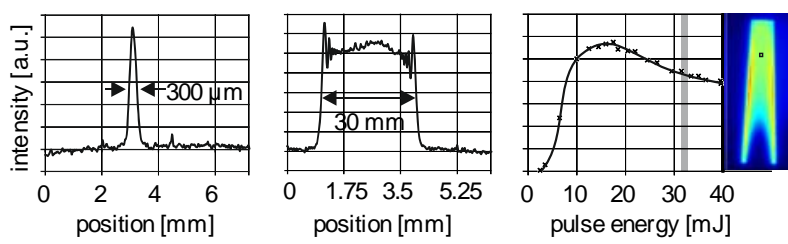

Fig. 2: Laser sheet characteristics as determined with a beam profiler (left, centre). The right plot shows the LII response curve measured in a stable laminar diffusion flames (evaluation rectangle is labeled in flame image) and the chosen pulse energy of $32 \mathrm{~mJ}$.
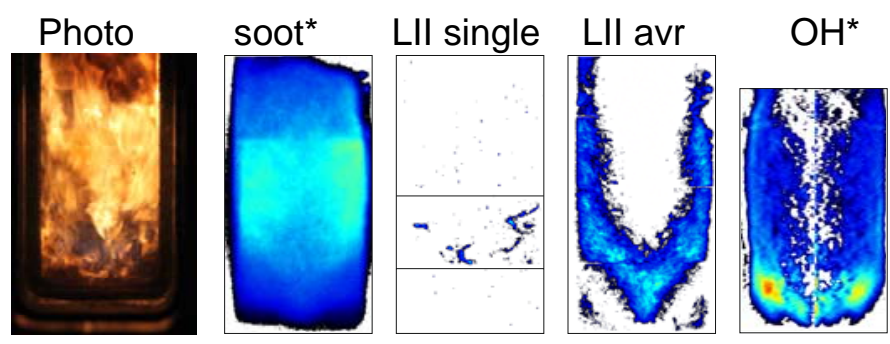

Fig. 3: Different information available for one exemplary flame at $p=3 \mathrm{bar}, \phi=1.2, P=30 \mathrm{~kW}, Q_{\text {air,c }} / Q_{\text {air }}=0.3$, $Q_{\text {oxi }} / Q_{\text {air }}=0.4$ (reference case). From left to right: Photo (exposure $500 \mu \mathrm{s}$ ), time averaged image of soot luminosity (integrated along line of sight, also available as instantaneous images), single shot of LII signal for one sheet position, averaged LII image (400 laser pulses) and time-averaged, deconvoluted $\mathrm{OH}$ chemiluminescence. All LII images are $60.4 \mathrm{~mm} \times 113.8 \mathrm{~mm}$ large, the $\mathrm{OH}$ image measures $55.7 \mathrm{~mm}$ x $93.3 \mathrm{~mm}$. 

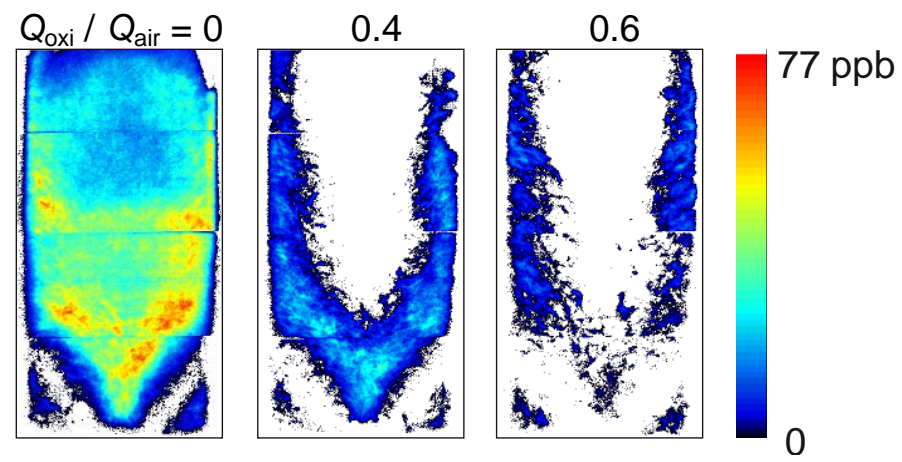

Fig. 4: Influence of a variation of oxidation air $Q_{\text {oxi }} / Q_{\text {air }}$ for operation at $p=3 \mathrm{bar}, \phi=1.2, P=30 \mathrm{~kW}, Q_{\text {air, }} / Q_{\text {air }}=$ 0.3 on the soot distribution (in ppb); the amount of oxidation air is indicated above the images.
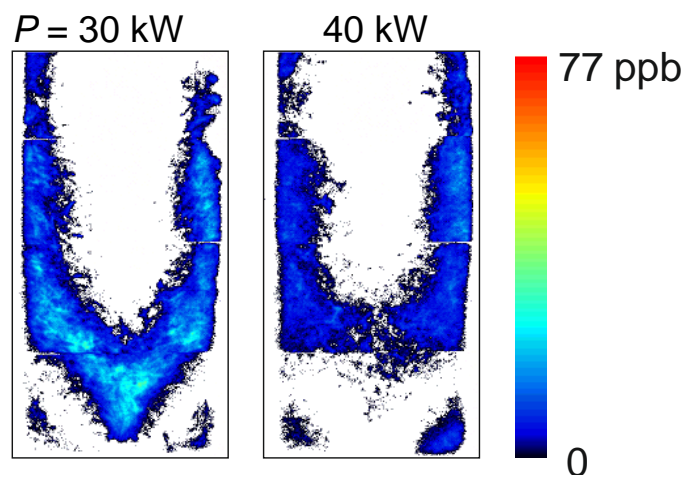

Fig. 5: Influence of a variation of flame power $P$ for operation at $p=3$ bar, $\phi=1.2, Q_{\text {air,c }} / Q_{\text {air }}=0.3, Q_{\text {oxi }} /$ $Q_{\text {air }}=0.4$ on the soot distribution (in ppb). This corresponds to an increase of the respective Reynolds number by one third. The flame power is indicated above the images. 
$Q_{\text {air, }} / Q_{\text {air }}=0.1 \quad 0.3$

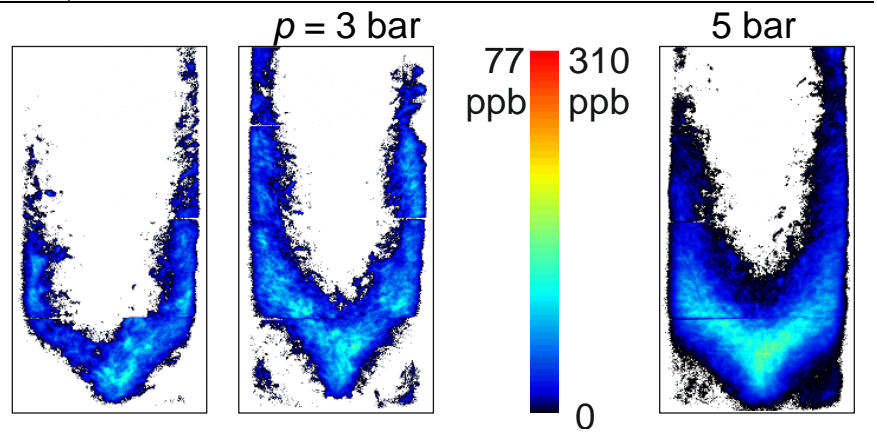

Fig. 6: Variation of air split $Q_{\text {air,c }} / Q_{\text {air }}$ for operation at $p$ $=3$ bar, $\phi=1.2, P=30 \mathrm{~kW}, Q_{\text {oxi }} / Q_{\text {air }}=0.4$ (left and central image, values of air split are listed in the top row above the images).

Variation of pressure $p$ for flames at $\phi=1.2, P=30 \mathrm{~kW}$, $Q_{\text {air,c }} / Q_{\text {air }}=0.3, Q_{\text {oxi }} / Q_{\text {air }}=0.4$ is compared between central and right image, both showing different soot concentration scales.

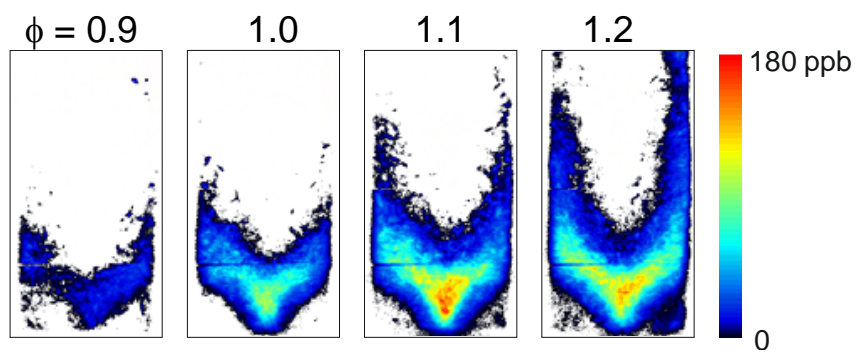

Fig. 7: Variation of equivalence ratio $\phi$ for operation at $p$ $=5 \mathrm{bar}, P=50 \mathrm{~kW}, Q_{\text {air, }} / Q_{\text {air }}=0.3, Q_{\text {oxi }} / Q_{\text {air }}=0.4$. 


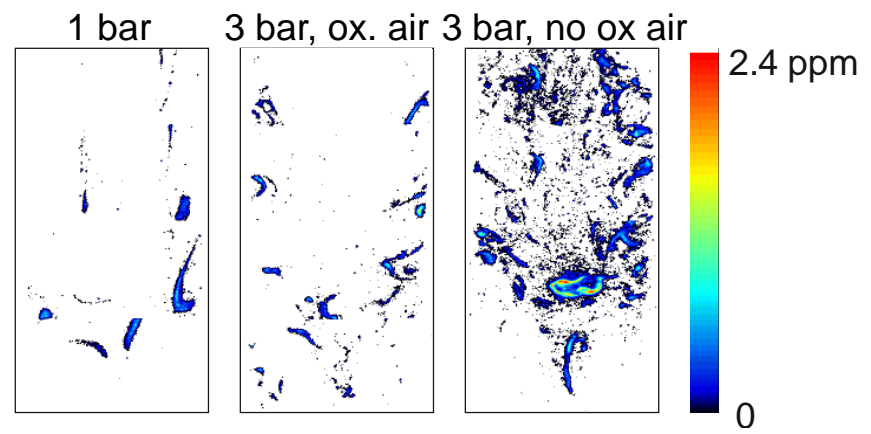

Fig. 8: Instantaneous soot volume fraction images (ppm) composed of arbitrarily selected images for each laser sheet position for the 1 bar ignition flame (left), the reference flame (centre) and the respective flame without oxidation air (time averages of the latter two are presented in Fig. 4). 


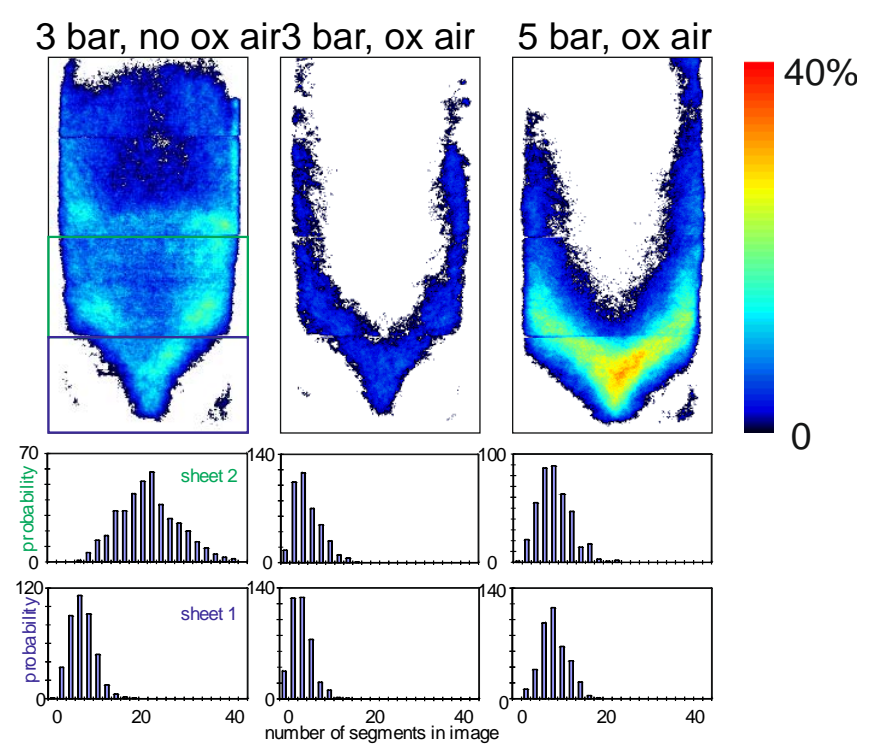

Fig. 9: Probability within image sequences of finding soot in a single location. The central image represents the reference flame, variation to the left is without oxidation air (zero), to the right is pressure ( 5 bars). The bottom rows display statistics over the number of soot filaments per instantaneous image, plotted for the 2nd laser sheet position (2nd row), and the lowest position (bottom). 

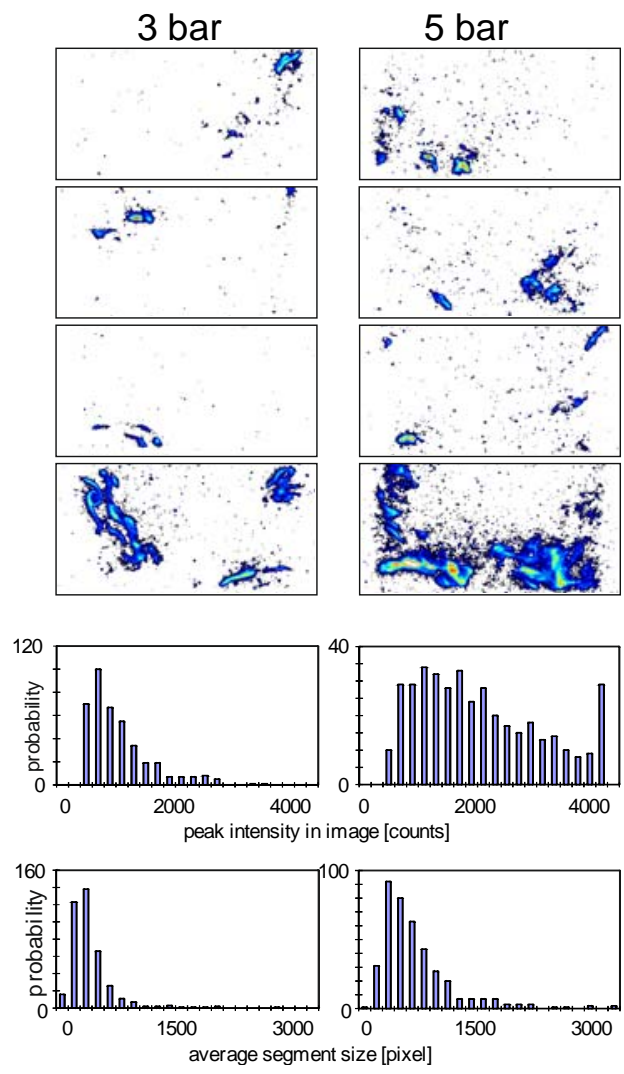

Fig. 10: Instantaneous image statistics for reference flame at 3 bars (left) and pressure variation (5 bars, right). Upper images show three representative and one particularly strong single shot image, histograms visualize probabilities for peak intensities in images (upper panel) and average segment size (lower panel). 